\title{
OPEN
}

\section{Publisher Correction: Synthesis of Saccharumoside-B analogue with potential of antiproliferative and pro-apoptotic activities}

Srinuvasarao Rayavarapu, Nagendra Sastry Yarla, Sunanda Kumari Kadiri, Anupam Bishayee, Siddaiah Vidavalur, Ramu Tadikonda, Mahaboob Basha, Vijaya Rao Pidugu, Kaladhar S. V. G. K. Dowluru, Dhananjaya Bhadrapura Lakappa, Mohammad A. Kamal, Ghulam Md Ashraf, Vadim V. Tarasov, Vladimir N. Chubarev, Sergey G. Klochkov, George E. Barreto, Sergey O. Bachurin \& Gjumrakch Aliev

Correction to: Scientific Reports https://doi.org/10.1038/s41598-017-05832-w, published online 16 August 2017

In the original version of this Article, Ghulam Md Ashraf was incorrectly affiliated with 'Enzymoics and Novel Global Community Educational Foundation, Hebersham, NSW, Australia. The correct affiliation is listed below.

King Fahd Medical Research Center, King Abdulaziz University, Jeddah, Saudi Arabia.

Additionally, within the Supplementary Information file originally published with this Article, authors Vijaya Rao Pidugu, Mohammad A. Kamal, Ghulam Md Ashraf, Vadim V. Tarasov, Vladimir N. Chubarev, Sergey G. Klochkov, George E. Barreto and Sergey O. Bachurin were omitted.

These errors have now been corrected in the PDF and HTML versions of the Article, and in the accompanying Supplementary material.

\begin{abstract}
(c) (i) Open Access This article is licensed under a Creative Commons Attribution 4.0 International C. License, which permits use, sharing, adaptation, distribution and reproduction in any medium or format, as long as you give appropriate credit to the original author(s) and the source, provide a link to the Creative Commons license, and indicate if changes were made. The images or other third party material in this article are included in the article's Creative Commons license, unless indicated otherwise in a credit line to the material. If material is not included in the article's Creative Commons license and your intended use is not permitted by statutory regulation or exceeds the permitted use, you will need to obtain permission directly from the copyright holder. To view a copy of this license, visit http://creativecommons.org/licenses/by/4.0/.
\end{abstract}

(C) The Author(s) 2020 